\title{
Pure hemi-periareolar incision versus conventional lateral radial incision mastectomy and direct-to-implant breast reconstructions: comparison of indocyanine green angiographic perfusion and necrosis of the nipple
}

\author{
Jin-Woo Park ${ }^{1}$, Ik Hyun Seong ${ }^{1}$, Woosung Lim², Kyong-Je Woo ${ }^{1}$ \\ ${ }^{1}$ Department of Plastic and Reconstructive Surgery, ${ }^{2}$ Department of Surgery, Ewha Womans University Mokdong Hospital, College of Medicine, \\ Ewha Womans University, Seoul, Republic of Korea \\ Contributions: (I) Conception and design: JW Park, KJ Woo; (II) Administrative support: JW Park, IH Seong; (III) Provision of study materials or \\ patients: W Lim, KJ Woo; (IV) Collection and assembly of data: JW Park, IH Seong; (V) Data analysis and interpretation: JW Park, W Lim, KJ \\ Woo; (VI) Manuscript writing: All authors; (VII) Final approval of manuscript: All authors. \\ Correspondence to: Kyong-Je Woo, MD, PhD. Assistant Professor, Department of Plastic and Reconstructive Surgery, College of Medicine, Ewha \\ Womans University, 1071, Anyangcheon-ro, Yangcheon-gu, Seoul 07985, Republic of Korea. Email: economywoo@gmail.com.
}

Background: This study evaluated the feasibility of direct-to-implant breast reconstruction after nipplesparing mastectomy using pure hemi-periareolar incision without extension and with the aid of indocyanine green angiographic evaluation on the mastectomy skin flap.

Methods: Patients who underwent immediate direct-to-implant breast reconstruction from December 2018 to February 2020 were included. After nipple-sparing mastectomy, indocyanine green angiographic evaluation of perfusion to nipple-areola complex was performed by video recording with a near infrared camera, and nipple perfusion time and perfusion pattern were analyzed. Patients were divided into a pure hemi-periareolar incision group and conventional lateral radial incision groups to compare nipple perfusion and surgical outcomes.

Results: A total of 61 breasts in 56 patients were included. Pure hemi-periareolar incision was used in 41 breasts, and conventional lateral radial incisions were used in 20 breasts. Nipple perfusion time was significantly increased in the pure hemi-periareolar incision group $(79.6 \pm 65.8$ vs. $43.2 \pm 49.8$ seconds, $\mathrm{P}=0.031)$. While minor nipple-areola complex necrosis was significantly increased in the pure hemiperiareolar incision group $(19.5 \%$ versus $0 \% ; \mathrm{P}=0.044)$, major nipple-areola complex necrosis $(2.4 \%$ versus $5.0 \% ; \mathrm{P}>0.999)$ was not significantly different between the two groups. The rates of nipple-areola complex necrosis were $0 \%, 16.7 \%$, and $63.6 \%$ in rapid, delayed, and no perfusion groups, respectively $(\mathrm{P}<0.001)$. No nipple perfusion pattern was a significant predictor for nipple-areola complex necrosis in univariable and multivariable analyses $(\mathrm{P}<0.001)$. There was no case of reconstruction failure.

Conclusions: Immediate direct-to-implant breast reconstruction after nipple-sparing mastectomy using pure hemi-periareolar incision can be safely performed using indocyanine green angiographic evaluation on the mastectomy skin flap.

Keywords: Direct-to-implant breast reconstruction; nipple-sparing mastectomy; indocyanine green; nipple-areola complex necrosis; mastectomy skin flap

Submitted May 17, 2020. Accepted for publication Aug 19, 2020.

doi: 10.21037/gs-20-506

View this article at: http://dx.doi.org/10.21037/gs-20-506 


\section{Introduction}

Freeman introduced immediate breast reconstruction after mastectomy with preservation of the nipple-areola complex (NAC) in 1962 in a case series of reconstructions after subcutaneous mastectomies for benign breast disease (1). Historically, subcutaneous mastectomy often left significant breast tissue within the skin flaps and at the base of the NAC. This concept was not ideal for prophylaxis or breast cancer treatment and had questionable oncologic safety (2). In the 1990s and 2000s, nipple-sparing mastectomy (NSM) and immediate breast reconstruction was gradually introduced. This method gained popularity for both therapeutic and prophylactic indications based on oncologic and surgical safety evidence and superior cosmetic outcomes (2-5). Preservation of the NAC in NSM indicates that this procedure is both the most conservative mastectomy method and also the most aesthetically appealing as it ensures a natural-appearing nipple (6).

Several different incision types have been suggested for NSM (e.g., inframammary fold, radial, periareolar, transareolar, reduction/mastopexy). Among them, periareolar incision provides advantages of a well-hidden incision scar within the periphery of the NAC and central access to all breast quadrants during mastectomy (7). Furthermore, postoperative NAC malpositioning can be minimized, unlike with radial incisions. Despite these advantages, some surgeons are reluctant to choose periareolar incision, mainly due to the potential high rate of postoperative nipple necrosis $(8,9)$.

Studies have shown that intraoperative use of indocyanine green (ICG) angiography identifies areas of decreased perfusion and predicts mastectomy skin flap necrosis (10-14). Recently, Bilezikian et al. reported that prepectoral directto-implant (DTI) reconstruction can be safely performed in postmastectomy patients using ICG angiography and extended use of acellular dermal matrix (15). In this study, we present initial results of DTI breast reconstructions with acellular dermal matrix after NSM using pure hemiperiareolar incision with intraoperative ICG angiography. The secondary objective was to identify predictors for NAC necrosis by analyzing ICG angiographic perfusion images of the NAC. We present the following article in accordance with the STROBE reporting checklist (available at http:// dx.doi.org/10.21037/gs-20-506).

\section{Methods}

\section{Patient cobort}

Prospectively recorded data from consecutive patients who underwent immediate DTI reconstruction with an acellular dermal matrix after NSM at our institution between December 2018 and February 2020 were retrospectively reviewed. The study was approved by the Institutional Review Board of Ewha Womans University Mokdong Hospital (IRB No. 2020-03-028) and performed in accordance with the principles of the Declaration of Helsinki (as revised in 2013). Individual consent for this retrospective analysis was waived. Patients who were followed up for at least 1 month postoperatively were included. Patients who had a previous breast procedure, including breast conserving surgery for previous malignancy, augmentation mammoplasty, mastopexy, and reduction mammoplasty, and a history of radiation therapy were excluded from this study. Three experienced oncologic surgeons with over 10 years of experience performed mastectomy, and the senior author (KJW) performed reconstructions.

\section{Surgical technique}

The method of skin incision for mastectomy was selected based on surgeon preference, breast size, areola size, and tumor location. Three skin incision methods were used, including pure hemi-periareolar incision, lateral radial incision, and lateral radial incision with periareolar extension. Mastectomy using pure hemi-periareolar incision was performed using a semicircular incision along the NAC and no extensions, as previously described (Figure 1) (16). Indications for pure hemi-periareolar incisions include mastectomy candidates without nipple-areolar complex invasion (17).

Electrocautery dissection was used for all mastectomy procedures, and endoscopic devices were not used. The extent of dissection for mastectomy did not exceed the inframammary fold inferiorly, and sizable intercostal perforators at the $2 \mathrm{nd}$ or $3 \mathrm{rd}$ intercostal spaces were preserved medially to minimize necrosis of the mastectomy skin flap. After mastectomy, a breast sizer of similar size to the mastectomy specimen was temporarily placed in the mastectomy pocket. While the temporary sizer was 

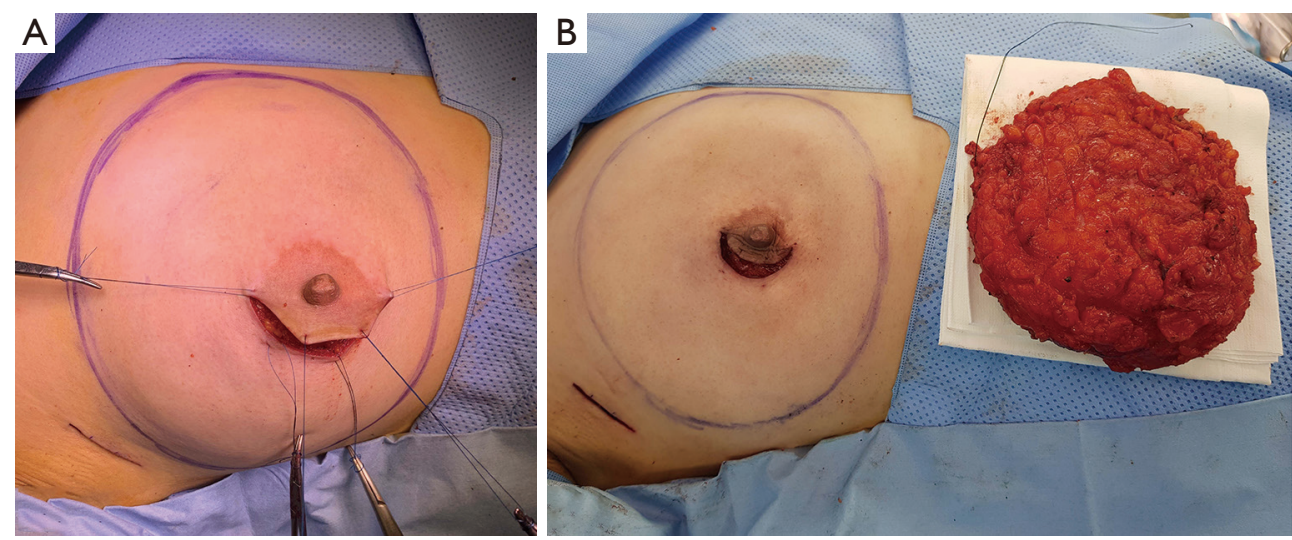

Figure 1 Nipple-sparing mastectomy using pure hemi-periareolar incision. (A) A semicircular incision along the nipple-areolar complex was made. (B) Photograph taken after completion of nipple sparing mastectomy with pure hemi-periareolar incision.

in place, nipple perfusion was evaluated using a nearinfrared camera (Moment K; IANC\&S, Seoul, Korea). After administering $12.5 \mathrm{mg}$ of ICG (25 mg ICG mixed with $5 \mathrm{~mL}$ normal saline, Dongindang Pharm., Siheung, Korea) followed by a $10 \mathrm{~mL}$ saline flush, video recordings were obtained from when fluorescence was started to visualize the mastectomy skin flap. Recordings continued for 180 seconds. DTI reconstruction proceeded if any fluorescence was observed in the lateral half of the areola (at least $50 \%$ of areola) by ICG angiography. In patients who could not afford a large acellular dermal matrix, had a thin mastectomy skin flap which can cause significant rippling, or had decreased areolar perfusion by ICG angiography, the implant was placed in the subpectoral space. An acellular dermal matrix (human cadaveric) was used for inferior and lateral support and implant coverage. Otherwise, implants were completely wrapped with the $16 \mathrm{~cm} \times 16 \mathrm{~cm}$ or $18 \mathrm{~cm} \times 18 \mathrm{~cm}$ acellular dermal matrix (human cadaveric), and the wrapped implant was placed in pre-pectoral spaces without suture fixation. Two closed suction drains were placed in the subpectoral and prepectoral spaces for subpectoral reconstruction and in the upper and lower pole of the prepectoral spaces for prepectoral reconstruction. Partial trimming of the areola for a width of 1 to 5 millimeters was determined by ICG angiographic findings, and mastectomy skin flaps with a width of 1 millimeter were performed in a routine manner to avoid compromised skin margins. Drains were removed when the drainage amount was less than $30 \mathrm{~mL}$ over 24 hours for two consecutive days. Prophylactic antibiotics were administrated until drain removal.

\section{Data collection}

Patients were divided into two cohorts of pure hemiperiareolar incision and conventional lateral radial incision groups. Clinical characteristics, operative characteristics, and surgical outcomes were compared between the two groups. The primary outcome was development of NAC necrosis, including major and minor necrosis. Major necrosis was defined as full-thickness necrosis requiring surgical intervention. Minor necrosis was defined as partialthickness necrosis treated with conservative management. Other postoperative complications, including seroma, hematoma, and infection, were also assessed.

ICG angiographic findings were reviewed with video clips to identify clinically relevant variables of NAC necrosis. Nipple perfusion time was defined as the time interval between visualizing fluorescence on the mastectomy skin flap and nipple and measured. Nipple perfusion time was recorded as 180 seconds when the nipple was not visualized for 180 seconds. Patients were divided into three groups: rapid perfusion, delayed perfusion, and no perfusion. Rapid perfusion was defined as nipple perfusion time less than the median value of overall patients. Delayed perfusion was defined as nipple perfusion time equal to or more than the median value, but less than 180 seconds. No perfusion was defined as when the nipple was not visualized for 180 seconds.

\section{Statistical analysis}

Mean and standard deviation were used to summarize continuous variables, and frequency and proportion were 
used to demonstrate categorical variables. Clinical and operative variables were compared between groups using two-sample $t$-test or Mann-Whitney $\mathrm{U}$ test for continuous variables and Fisher's exact test and linear-by-linear association test for categorical variables. The selection of statistic test was based on the results of normality test. Binary logistic regression analysis was performed to analyze the effect of each clinical variable on binary outcomes. Variables with $\mathrm{P}<0.20$ in univariable analysis were entered into a multivariate analysis. Multivariate analysis was performed using stepwise logistic regression, and adjusted odd ratios were reported with $95 \%$ confidence intervals. Statistical significance was determined by $\mathrm{P}<0.05$. All analyses were performed using SPSS version 23.0 (SPSS Inc., Chicago, IL, USA).

\section{Results}

Among 60 patients who underwent DTI breast reconstructions after NSM in the study period, 56 met the inclusion criteria and were included in this study. Two patients were excluded due to previous augmentation mammoplasty, and the remaining 2 patients had a history of breast conserving surgery. The 56 patients with an average age of 46.8 years old (range, 32 to 64 years) had 61 DTI breast reconstructions following NSM using pure hemiperiareolar incision $(n=41)$ or conventional lateral radial incisions $(n=20)$, including radial incision $(n=15)$ and lateral radial incision with periareolar extension $(\mathrm{n}=5)$. The average body mass index was $22.3 \mathrm{~kg} / \mathrm{m}^{2}$ (range, 17.7 to 27.2 ), and implant volume was $296.5 \mathrm{~mL}$ (range, 150 to $550 \mathrm{~mL}$ ). There were no significant differences between the pure hemi-periareolar incision group and the conventional lateral radial incision group in age, body mass index, hypertension, diabetes, smoking history, previous chemotherapy, mastectomy specimen weight, implant volume and position, sternal notch to nipple distance, and surgery duration. Sentinel lymph node biopsy was performed more often in the pure hemi-periareolar incision group than in the conventional lateral radial incision group $(78.0 \%$ versus $35.0 \%$ ), and axillary lymph node dissection was performed more in the conventional lateral radial incision group than in the pure hemi-periareolar incision group $(14.0 \%$ versus $60.0 \%$ ). Differences in lymph node management between the two groups were significant $(\mathrm{P}=0.001)$. Duration of drain use was significantly decreased in the pure hemiperiareolar incision group compared to the conventional lateral radial incision group (9.9 versus 12.1 days; $\mathrm{P}=0.007$ )
(Table 1).

The complication profiles of the pure hemi-periareolar incision group and conventional lateral radial incision group are summarized in Table 2. Development of NAC necrosis was more common in the pure hemi-periareolar incision group than in the conventional lateral radial incision group, but the difference was not statistically significant $22.0 \%$ versus $5.0 \%$, respectively; $\mathrm{P}=0.144)$. Among NAC necrosis components, minor necrosis was significantly increased in the pure hemi-periareolar incision group compared to the conventional lateral radial incision group $(19.5 \%$ versus $0 \%$, respectively; $\mathrm{P}=0.044$ ), while major necrosis was not significantly different between the two groups (2.4\% versus $5.0 \%$, respectively; $\mathrm{P}>0.999)$. There were no significant differences between the two groups in incidence of seroma, hematoma, and infection $(\mathrm{P}>0.999)$. Overall complication rate was also not significantly different between the two groups $(22.0 \%$ versus $5.0 \%$, respectively; $\mathrm{P}=0.144)$. No reconstruction failure was observed in either group $(\mathrm{P}>0.999)$.

Evaluation of ICG angiographic variables showed that median nipple perfusion time was 36.0 seconds. This was used as a reference point to divide rapid perfusion and delayed perfusion groups (Video 1). The mean nipple perfusion time was significantly increased in the pure hemiperiareolar incision group compared to the conventional lateral radial incision group (79.6 versus 43.2 seconds; $\mathrm{P}=0.031$ ), but the nipple perfusion pattern was not significantly different between the two groups $(\mathrm{P}=0.226$; Table 3). Subgroup analysis was then performed to evaluate the association between ICG angiographic variables and NAC necrosis in the pure hemi-periareolar incision group. Patients were divided into two groups, the NAC necrosis group ( $n=9)$ and no necrosis group ( $n=32)$. Nipple perfusion time was significantly higher in the NAC necrosis group than in the no necrosis group (166.0 versus 55.3 seconds; $\mathrm{P}<0.001$; Figure 2). The rapid, delayed, and no perfusion groups showed $0 \%$ (0/17 breasts), $22.2 \%$ (2/15 breasts), and $77.8 \%$ (7/9 breasts) incidence rates of NAC necrosis, respectively. Differences in the NAC necrosis rate among the three perfusion patterns were statistically significant $(\mathrm{P}<0.001$; Figure 3$)$.

In univariable analysis, nipple perfusion time (OR 1.027; 95\% CI: $1013-1.042$; $\mathrm{P}<0.001)$ and nipple perfusion pattern (OR 5.236; 95\% CI: 2.244-12.217; $\mathrm{P}<0.001)$ were significantly associated with the development of NAC necrosis (Table 4). In multivariable analysis, nipple perfusion pattern was the only predictor for NAC necrosis 
Table 1 Clinical and surgical characteristics

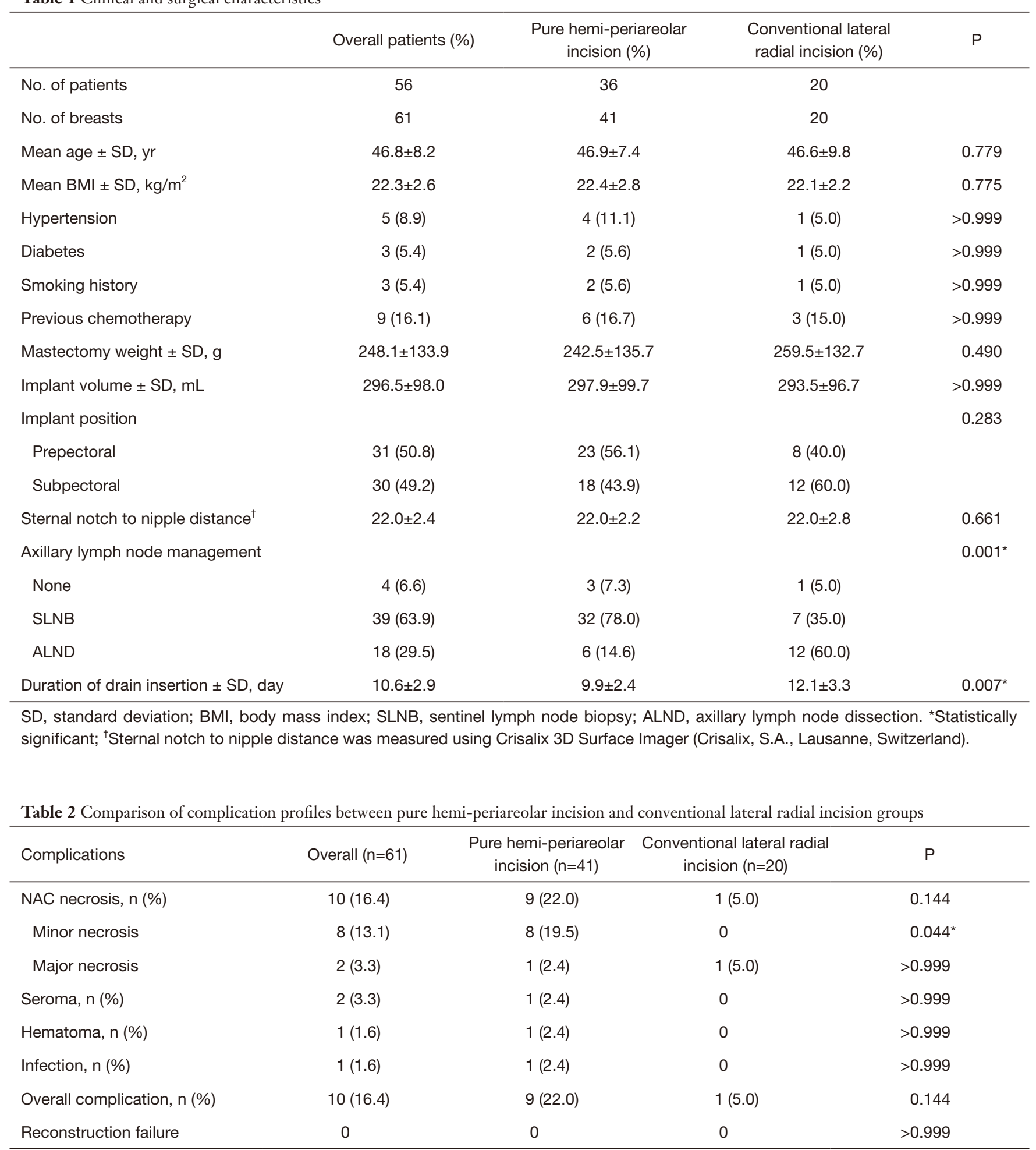

NAC, nipple-areola complex. *Statistically significant. 
Table 3 Comparison of indocyanine green angiographic variables between pure hemi-periareolar incision and conventional lateral radial incision groups

\begin{tabular}{lccc}
\hline Complications & Overall $(\mathrm{n}=61)$ & $\begin{array}{c}\text { Pure hemi-periareolar } \\
\text { incision }(\mathrm{n}=41)\end{array}$ & $\begin{array}{c}\text { Conventional lateral radial } \\
\text { incision }(\mathrm{n}=20)\end{array}$ \\
\hline $\begin{array}{l}\text { Nipple perfusion time } \pm \mathrm{SD} \text {, seconds } \\
\text { Nipple perfusion pattern, } \mathrm{n}(\%)\end{array}$ & $67.6 \pm 63.0$ & $79.6 \pm 65.8$ & $43.2 \pm 49.8$ \\
$\begin{array}{l}\text { Rapid perfusion } \\
\text { Delayed perfusion }\end{array}$ & $30(49.2)$ & $17(41.5)$ & $13(65.0)$ \\
No perfusion & $20(32.8)$ & $15(36.6)$ & $5(25.0)$ \\
\hline
\end{tabular}

$\mathrm{SD}$, standard deviation. *Statistically significant.

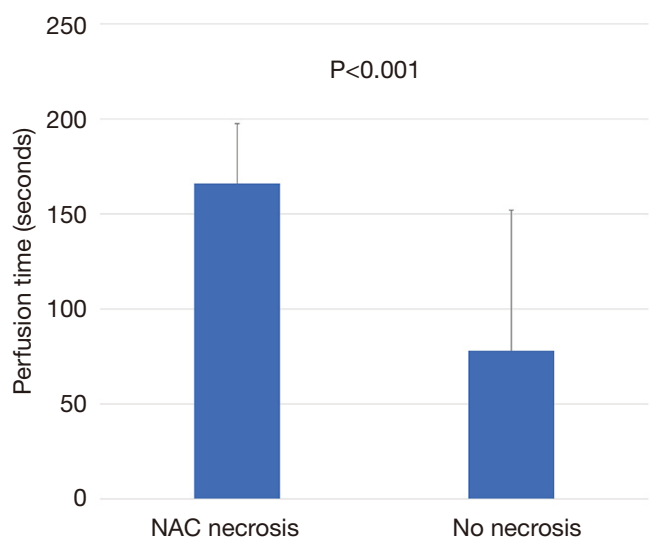

Figure 2 Nipple perfusion time was compared between NAC necrosis group ( $n=9)$ and no necrosis group $(n=32)$ in subgroup analysis of patients with pure hemi-periareolar incision. NAC necrosis group showed significantly increased perfusion time compared to no necrosis group $(\mathrm{P}<0.001)$. NAC, nipple-areola complex.

with statistical significance (Table 5). The odds of NAC necrosis in the no perfusion group was 5.2 times that in the other perfusion pattern group. Figures 4,5 show example preoperative and postoperative photographs of patients undergoing DTI reconstructions after mastectomy using pure hemi-periareolar incisions.

\section{Discussion}

We demonstrated the surgical outcomes of DTI breast reconstructions after NSM using pure hemi-periareolar incision without extension. Complications of the mastectomy skin flap were minimized with intraoperative evaluation of mastectomy skin flap circulation by ICG

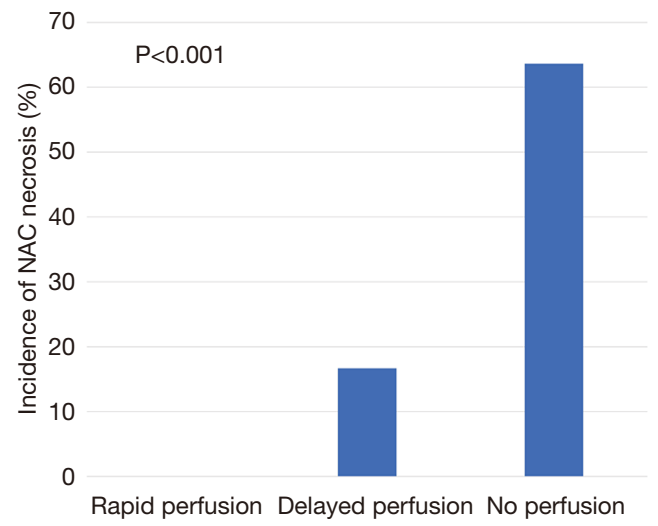

Figure 3 In analysis of perfusion pattern, significant differences in incidence of NAC necrosis were observed among rapid, delayed, and no perfusion groups $(0 / 17,2 / 15$, and $7 / 9$ breasts, respectively; $\mathrm{P}<0.001)$. NAC, nipple-areola complex.

angiography. In the pure hemi-periareolar incision group, full-thickness necrosis of the NAC was observed in only $2.4 \%$ of cases (1/41 cases) and all 8 cases of minor necrosis $(19.5 \%)$ healed spontaneously with conservative management. By using pure hemi-periareolar incisions, each procedure achieved dual aims of extirpative surgery and breast reconstruction. All four quadrants of the breast and axillary lymph nodes were adequately accessed when performing extirpative procedures for breast cancer because of central access provided by the incision. For breast reconstruction, visible scar was minimized and nipple malpositioning could be prevented, which can result from scar contracture in radial incisions.

Several incision methods have been suggested for NSM, including radial, inframammary fold, periareolar, transareolar, and reduction/mastopexy incisions. The inframammary fold incision is currently gaining popularity 
Table 4 Univariable analysis of clinical and indocyanine green angiographic variables for nipple-areola complex necrosis

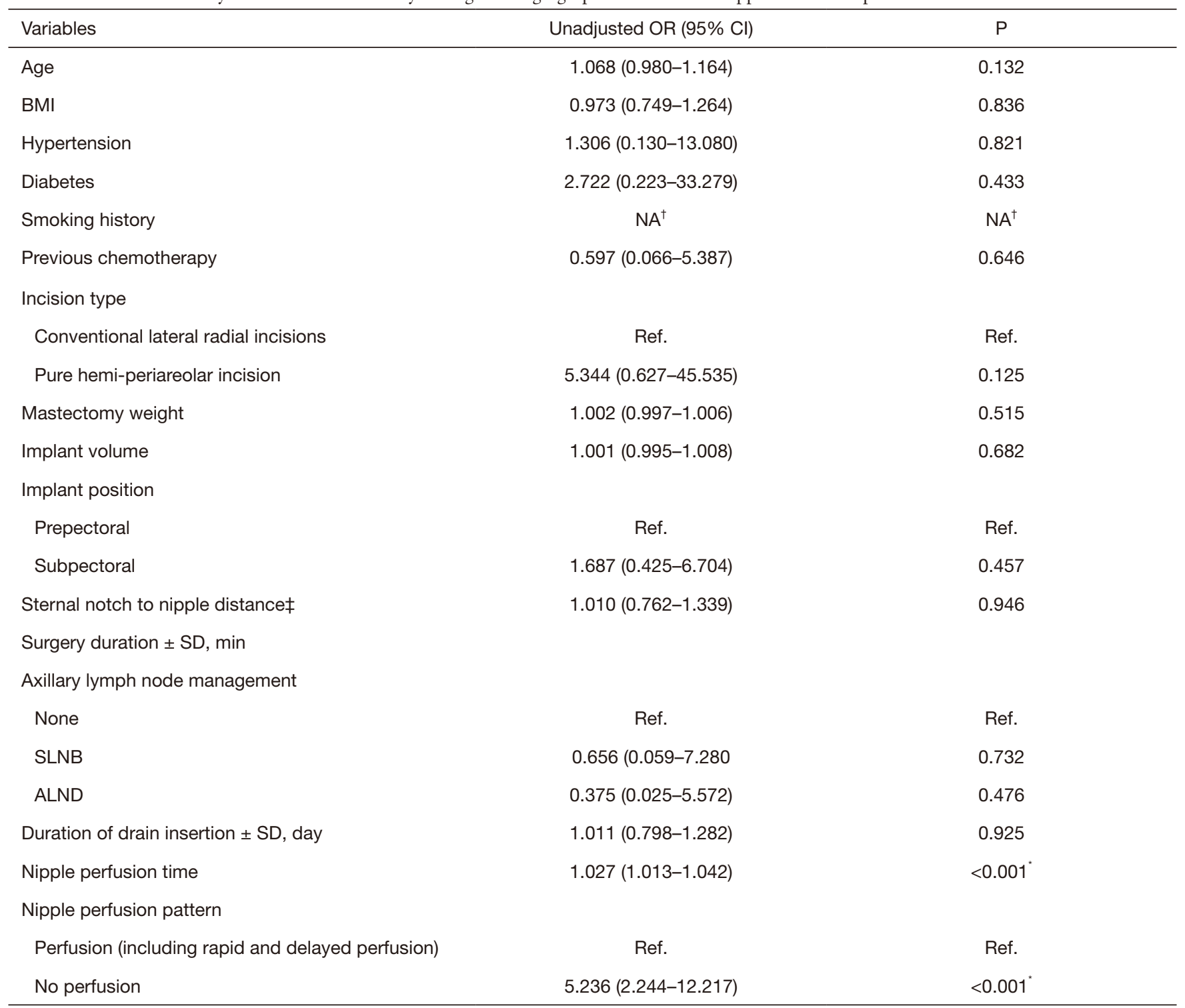

OR, odds ratio; Cl, confidence interval; BMI, body mass index; SD, standard deviation; SLNB, sentinel lymph node biopsy; ALND, axillary lymph node dissection. *Statistically significant; ${ }^{\dagger}$ Not available according to the lack of events in the nipple-areola complex necrosis group; ${ }^{\ddagger}$ Sternal notch to nipple distance was measured using Crisalix 3D Surface Imager (Crisalix, S.A., Lausanne, Switzerland).

for several advantages, including direct visualization and tailoring of the inframammary fold, less tension on incision edges with retraction, and acceptable incision scar (9). However, adequate access to the upper breast pole is more challenging via inframammary incision, and long incision is usually required for oncologic resection $(9,18)$. Furthermore, a separate axillary incision for axillary lymph node dissection along with the long inframammary fold incision may cause perfusion-related complications in the inferior mastectomy skin flap and NAC $(19,20)$. Conversely, periareolar incisions provide central access to all breast quadrants during mastectomy and, when necessary, to the axilla for sentinel lymph node biopsy and axillary dissections (17). Furthermore, the scar can be well-hidden within the periphery of the areola because of different color and texture of the areola and surrounding skin. However, the main disadvantage of the periareolar incision is the high rate of nipple-areola necrosis, which ranged from $9 \%$ 
Table 5 Multivariable analysis of clinical and indocyanine green angiographic variables for nipple-areola complex necrosis

\begin{tabular}{lcc}
\hline & Adjusted OR (95\% Cl) & - \\
\hline Age & - & P \\
Incision type & Ref. & Ref. \\
Conventional lateral radial incisions & - & - \\
Pure hemi-periareolar incision & Ref. & Ref. \\
Nipple perfusion pattern & $5.236(2.244-12.217)$ & $<0.001^{*}$ \\
Perfusion (including rapid and delayed perfusion) &
\end{tabular}

OR, odds ratio; $\mathrm{Cl}$, confidence interval. *Statistically significant.
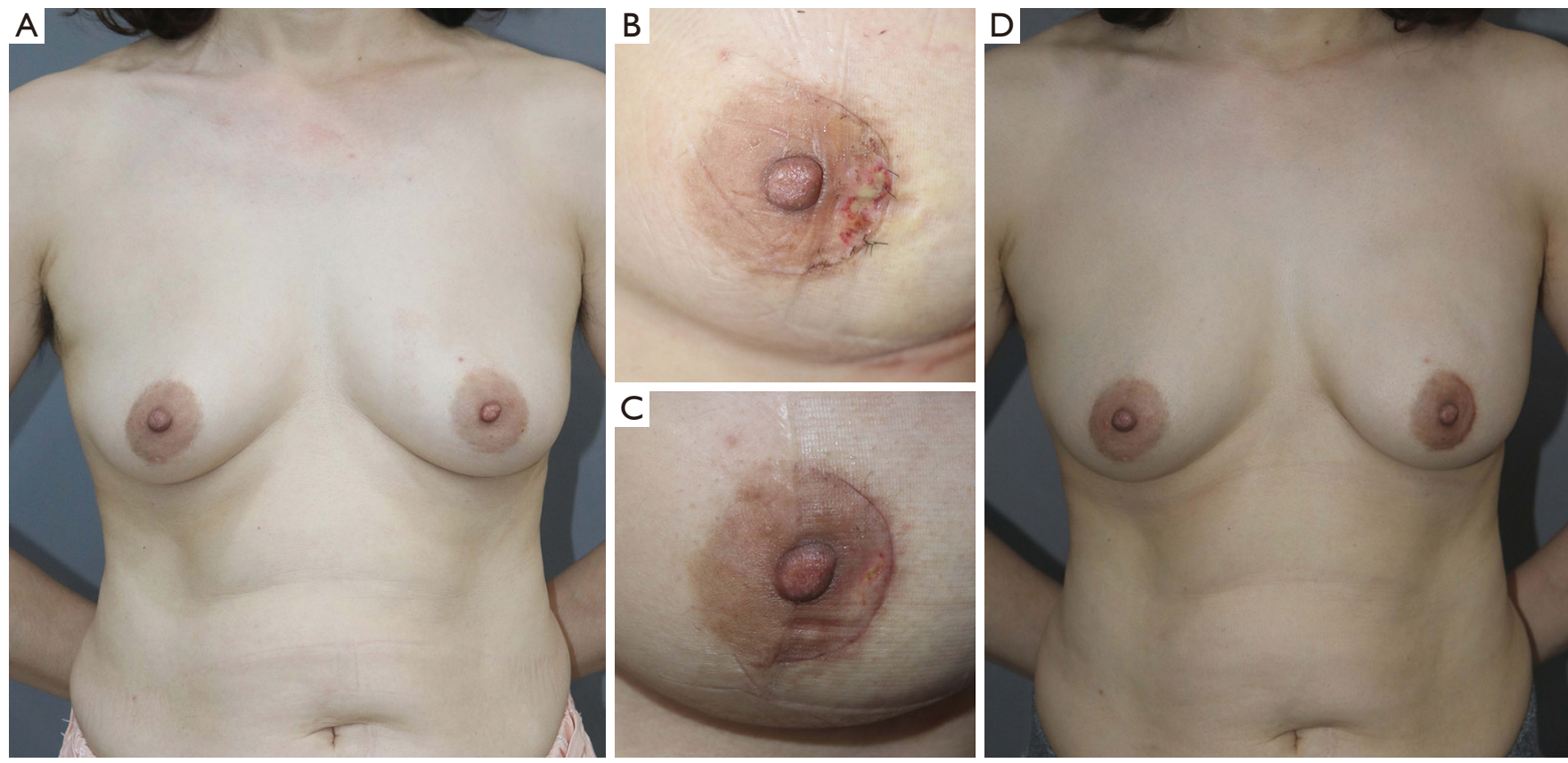

Figure 4 A 48-year-old woman underwent prepectoral direct-to-implant breast reconstruction after nipple-sparing mastectomy with pure hemi-periareolar incision on her left breast. (A) Preoperative view. (B) 2-week postoperative view. Partial-thickness necrosis developed on lateral areola. (C) 4-week postoperative view. Partial-thickness necrosis completely healed with conservative management. (D) 4-month postoperative view.

to $29 \%$ in a meta-analysis (9). To minimize the risk of nipple-areola necrosis after mastectomy using peri-areolar incision, intraoperative assessment of ICG angiography was performed to aid decision making for reconstruction. This included whether to proceed with the reconstructive procedure, determination of surgical plane for implant placement, and amount of partial trimming for circulationcompromised areolar skin.

Several studies have been conducted using ICG angiography to objectively evaluate perfusion of the mastectomy skin flap to predict skin flap necrosis (10-12, 21-25). All studies have evaluated perfusion of mastectomy skin flaps using fluorescence intensity. Gorai et al. also assessed time and rate of increase to reach maximum perfusion (24). Although fluorescence intensity has been demonstrated as a useful predictor for postoperative mastectomy skin flap necrosis, several potential drawbacks should be considered. The absolute values of fluorescence 

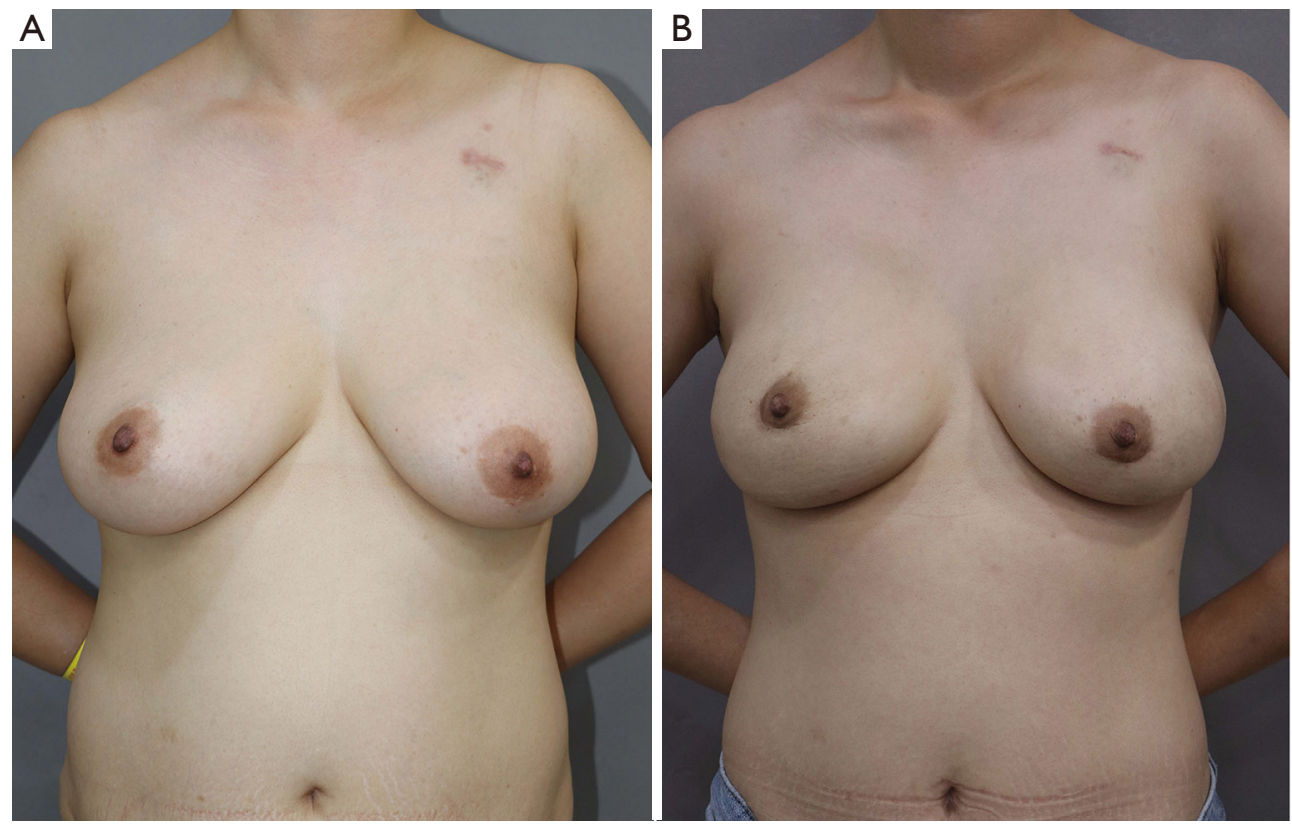

Figure 5 A 37-year-old woman underwent subpectoral direct-to-implant breast reconstruction after nipple-sparing mastectomy using pure hemi-periareolar incision on bilateral breasts. (A) Preoperative view. (B) 6-month postoperative view.

considered to be predictive for necrosis vary greatly among studies. These values can be influenced by measurement tools and surrounding circumstances, such as ambient lighting in the operation theater (26). There are generalization issues for fluorescence intensity because intensities obtained by various fluorescence imaging systems have different values and cannot be compared with each other without additional correlation study (23).

Conversely, time-related variables, such as perfusion time, rate of increase, and perfusion velocity, have rarely been investigated. Erni et al. observed significant reduction in the perfusion velocity of microcirculation of the ischemic flap at 1 hour after surgery using an extended flap model in the experimental setting (27). In a retrospective study of ICG angiographic evaluation of the mastectomy skin flap after immediate tissue expander reconstruction, Gorai et al. showed that the rate of increase to reach maximum perfusion is a more sensitive parameter than fluorescence intensity (24). In this study, we demonstrated that perfusion time was significantly increased in the NAC necrosis group compared to the no necrosis group, and the rates of NAC necrosis were significantly different between the three groups with different perfusion velocity, including rapid, delayed, and no perfusion. Time-related measurements have several advantages. These measurements can be easily applied to clinical settings, and the results can be compared to measurements of another instrument without a correlation process. Time-related measurements do not require a reference value, whereas fluorescence intensity does usually require a reference value. In addition, the reference value is variable and unpredictable in circulatory compromised mastectomy skin flaps (21). Finally, the measurements do not require special equipment or software to quantify fluorescence and only require an ICG camera. We believe that time-related measurements, such as perfusion time, rate of increase, and perfusion velocity, are suitable indictors for perfusion of mastectomy skin flap and NAC.

We suggest several strategies regarding the use of intraoperative ICG angiography to minimize the risk of NAC necrosis in DTI breast reconstruction after NSM using pure hemi-periareolar incision. DTI can be safely performed in patients with $50 \%$ or more of NAC visualized by ICG angiography after mastectomy. When perfusion was confirmed to cross the nipple, total nipple necrosis did not occur, even with no perfusion pattern of the nipple. Alternatively, staged expander/implant reconstruction should be considered with cases in which less than half of the NAC is visualized. Among patients with $50 \%$ or more of the NAC visualized by ICG angiography, prepectoral reconstruction can be safely performed in patients with 
rapid perfusion pattern. Prepectoral reconstruction can be performed for patients with delayed or no perfusion patterns, but meticulous efforts are required to minimize skin tension and maintain perfusion of the mastectomy skin flap. For breasts with no perfusion pattern of the nipple, NAC necrosis was more than 5 times more likely than in breasts with rapid or delayed perfusion patterns. Subpectoral reconstruction can be considered with no nipple perfusion pattern to avoid direct exposure of the implant in cases of possible major NAC necrosis. When significantly reduced or no perfusion areas were found in the areolar margin of the incision, trimming of the areolar margin by 1 to $5 \mathrm{~mm}$ may facilitate wound healing.

The current study had several limitations. Other variables that may affect outcomes were possibly omitted due to the retrospective study design. For example, core temperature of patients and environment temperature were not measured when performing ICG angiography, but these temperatures could affect peripheral circulation and measurements of ICG angiography. Breast measurements such as sternal notch to nipple distance and degree of ptosis could also be associated with NAC necrosis because NAC perfusion after NSM is dependent only on the skin flap perfusion and a greater distance from the chest wall to the nipple could increase NAC necrosis (28-30). According to the result of this study, sternal notch to nipple distance was not a significant predictor for NAC necrosis. However, the result needs further validation because sternal notch to nipple distance was obtained retrospectively using an automated $3 \mathrm{D}$ program in a relatively small number of study population in this study. The small number of cases included in this study is another limitation. Major NAC necrosis was not significantly different between the pure hemi-periareolar incision and conventional lateral radial incision groups, but only 1 patient in each group developed major necrosis. Further larger studies are warranted to confirm that DTI reconstruction after mastectomy using pure hemi-periareolar incision is feasible for breast reconstruction. Finally, the study population was limited to Asian women. Relatively low BMI and low mastectomy specimen weight might be associated with favorable outcomes. We believe that pure hemi-periareolar incision is feasible for large breasts (up to $738 \mathrm{~g}$ in this series) as well, but further studies in patients with relatively large breasts are necessary.

\section{Conclusions}

DTI breast reconstruction after NSM using pure hemi- periareolar incision can be safely performed with intraoperative evaluation of the mastectomy skin flap by ICG angiography. Nipple perfusion time and patterns suggested in this study may be useful predictors for NAC necrosis.

\section{Acknowledgments}

We would like to thank EssayReview (www.essayreview. co.kr) for English language editing.

Funding: None.

\section{Footnote}

Reporting Checklist: The authors have completed the STROBE reporting checklist. Available at http://dx.doi. org/10.21037/gs-20-506

Data Sharing Statement: Available at http://dx.doi. org/10.21037/gs-20-506

Conflicts of Interest: All authors have completed the ICMJE uniform disclosure form (available at http://dx.doi. org/10.21037/gs-20-506). The authors have no conflicts of interest to declare.

Ethical Statement: The authors are accountable for all aspects of the work in ensuring that questions related to the accuracy or integrity of any part of the work are appropriately investigated and resolved. The study was approved by the Institutional Review Board of Ewha Womans University Mokdong Hospital (IRB No.: 202003-028) and performed in accordance with the principles of the Declaration of Helsinki (as revised in 2013). Individual consent for this retrospective analysis was waived.

Open Access Statement: This is an Open Access article distributed in accordance with the Creative Commons Attribution-NonCommercial-NoDerivs 4.0 International License (CC BY-NC-ND 4.0), which permits the noncommercial replication and distribution of the article with the strict proviso that no changes or edits are made and the original work is properly cited (including links to both the formal publication through the relevant DOI and the license). See: https://creativecommons.org/licenses/by-nc-nd/4.0/.

\section{References}

1. Freeman BS. Subcutaneous mastectomy for benign breast 
lesions with immediate or delayed prosthetic replacement. Plast Reconstr Surg Transplant Bull 1962;30:676-82 .

2. Babiera G, Simmons R. Nipple-areolar complex-sparing mastectomy: feasibility, patient selection, and technique. Ann Surg Oncol 2010;17 Suppl 3:245-8.

3. Laronga C, Kemp B, Johnston D, et al. The incidence of occult nipple-areola complex involvement in breast cancer patients receiving a skin-sparing mastectomy. Ann Surg Oncol 1999;6:609-13.

4. Gerber B, Krause A, Dieterich M, et al. The oncological safety of skin sparing mastectomy with conservation of the nipple-areola complex and autologous reconstruction: an extended follow-up study. Ann Surg 2009;249:461-8.

5. Wu ZY, Kim HJ, Lee JW, et al. Breast Cancer Recurrence in the Nipple-Areola Complex After Nipple-Sparing Mastectomy With Immediate Breast Reconstruction for Invasive Breast Cancer. JAMA Surg 2019;154:1030-7.

6. El Hage Chehade H, Headon H, Wazir U, et al. Nipple-sparing mastectomy using a hemi-periareolar incision with or without minimal medial-lateral extensions; clinical outcome and patient satisfaction: A single centre prospective observational study. Am J Surg 2017;213:1116-24.

7. Rawlani V, Fiuk J, Johnson SA, et al. The effect of incision choice on outcomes of nipple-sparing mastectomy reconstruction. Can J Plast Surg 2011;19:129-33.

8. Endara M, Chen D, Verma K, et al. Breast reconstruction following nipple-sparing mastectomy: a systematic review of the literature with pooled analysis. Plast Reconstr Surg 2013;132:1043-54.

9. Daar DA, Abdou SA, Rosario L, et al. Is There a Preferred Incision Location for Nipple-Sparing Mastectomy? A Systematic Review and Meta-Analysis. Plast Reconstr Surg 2019;143:906e-19e.

10. Moyer HR, Losken A. Predicting mastectomy skin flap necrosis with indocyanine green angiography: the gray area defined. Plast Reconstr Surg 2012;129:1043-8.

11. Phillips BT, Lanier ST, Conkling N, et al. Intraoperative perfusion techniques can accurately predict mastectomy skin flap necrosis in breast reconstruction: results of a prospective trial. Plast Reconstr Surg 2012;129:778e-88e.

12. Munabi NC, Olorunnipa OB, Goltsman D, et al. The ability of intra-operative perfusion mapping with laserassisted indocyanine green angiography to predict mastectomy flap necrosis in breast reconstruction: a prospective trial. J Plast Reconstr Aesthet Surg 2014;67:449-55.

13. Komorowska-Timek E, Gurtner GC. Intraoperative perfusion mapping with laser-assisted indocyanine green imaging can predict and prevent complications in immediate breast reconstruction. Plast Reconstr Surg 2010;125:1065-73.

14. Hammer-Hansen N, Juhl AA, Damsgaard TE. Laserassisted indocyanine green angiography in implant-based immediate breast reconstruction: a retrospective study. J Plast Surg Hand Surg 2018;52:158-62.

15. Bilezikian JA, Tenzel PL, Bebb GG, et al. The Broad Application of Prepectoral Direct-to-Implant Breast Reconstruction with Acellular Dermal Matrix Drape and Fluorescent Imaging in a Community Setting. Plast Reconstr Surg 2020;145:291-300.

16. Paek SH, Hong SE, Woo KJ, et al. Nipple-sparing mastectomy through periareolar incision with immediate reconstruction. Ann Surg Treat Res 2020;98:57-61.

17. Paepke S, Schmid R, Fleckner S, et al. Subcutaneous mastectomy with conservation of the nipple-areola skin: broadening the indications. Ann Surg 2009;250:288-92 .

18. Salibian AH, Harness JK, Mowlds DS. Inframammary approach to nipple-areola-sparing mastectomy. Plast Reconstr Surg 2013;132:700e-8e.

19. Gould DJ, Hunt KK, Liu J, et al. Impact of surgical techniques, biomaterials, and patient variables on rate of nipple necrosis after nipple-sparing mastectomy. Plast Reconstr Surg 2013;132:330e-8e.

20. Margenthaler JA, Gan C, Yan Y, et al. Oncologic Safety and Outcomes in Patients Undergoing Nipple-Sparing Mastectomy. J Am Coll Surg 2020;230:535-41.

21. De Lorenzi F, Yamaguchi S, Petit JY, et al. Evaluation of skin perfusion after nipple-sparing mastectomy by indocyanine green dye. Preliminary results. J Exp Clin Cancer Res 2005;24:347-54.

22. Newman MI, Jack MC, Samson MC. SPY-Q analysis toolkit values potentially predict mastectomy flap necrosis. Ann Plast Surg 2013;70:595-8.

23. Phillips BT, Fourman MS, Rivara A, et al. Comparing quantitative values of two generations of laser-assisted indocyanine green dye angiography systems: can we predict necrosis? Eplasty 2014;14:e44.

24. Gorai K, Inoue K, Saegusa N, et al. Prediction of Skin Necrosis after Mastectomy for Breast Cancer Using Indocyanine Green Angiography Imaging. Plast Reconstr Surg Glob Open 2017;5:e1321.

25. Yang CE, Chung SW, Lee DW, et al. Evaluation of the Relationship Between Flap Tension and Tissue Perfusion in Implant-Based Breast Reconstruction Using LaserAssisted Indocyanine Green Angiography. Ann Surg Oncol 
2018;25:2235-40.

26. Driessen C, Arnardottir TH, Lorenzo AR, et al. How should indocyanine green dye angiography be assessed to best predict mastectomy skin flap necrosis? A systematic review. J Plast Reconstr Aesthet Surg 2020;73:1031-42.

27. Erni D, Sakai H, Banic A, et al. Quantitative assessment of microhemodynamics in ischemic skin flap tissue by intravital microscopy. Ann Plast Surg 1999;43:405-14; discussion 414-5.

28. Salibian AA, Frey JD, Karp NS. Strategies and

Cite this article as: Park JW, Seong IH, Lim W, Woo KJ. Pure hemi-periareolar incision versus conventional lateral radial incision mastectomy and direct-to-implant breast reconstructions: comparison of indocyanine green angiographic perfusion and necrosis of the nipple. Gland Surg 2020;9(5):11931204. doi: $10.21037 / g s-20-506$ considerations in selecting between subpectoral and prepectoral breast reconstruction. Gland Surg 2019;8:11-8.

29. Thuman J, Freitas AM, Schaeffer C, et al. Prepectoral Wise-Pattern Staged Implant-Based Breast Reconstruction for Obese or Ptotic Patients. Ann Plast Surg 2019;82:S404-9.

30. Maruccia M, Elia R, Gurrado A, et al. Skin-Reducing Mastectomy and Pre-pectoral Breast Reconstruction in Large Ptotic Breasts. Aesthetic Plast Surg 2020;44:664-72. 